\title{
Thoracic outlet syndrome presenting as an isolated external jugular vein engorgement
}

\author{
Jakub Kaczynski, Steve Atherton, Louis Fligelstone
}

Department of Vascular Surgery, ABM University Health Board, Swansea, UK

\section{Correspondence to} Jakub Kaczynski, jakub.kaczynski@hotmail.co.uk

\section{DESCRIPTION}

A 43-year-old man presented to the vascular surgery department with a 3-month history of right external jugular vein engorgement on upper limb elevation. The only medical history included previously sustained (10 years earlier) whip-plash injury following a road traffic accident. Physical examination confirmed external jugular vein engorgement along with reduced shoulder movements due to pain. Both Roos' and Adson's tests were positive. The clinical diagnosis of the venous thoracic outlet syndrome (vTOS) was made and subsequently confirmed by various investigations. The thoracic inlet radiograph revealed no abnormalities (figure 1). Ultrasound Duplex scan (UDS) demonstrated compression of the subclavian vein (SCV) under the clavicle on upper limb abduction. MRI showed mild narrowing with degenerative changes at the exit foramina of C6 and C7. Nerve conduction studies were unremarkable.

The patient underwent a supraclavicular decompression of thoracic outlet by the first rib excision and scalenectomy (figures 2 and 3). The operative findings confirmed the presence of an abnormal anatomy such as hypertrophied scalene muscles (anterior and middle) and tissue band compressing the SCV and subclavian artery (SCA) (figures 4 and 5). The

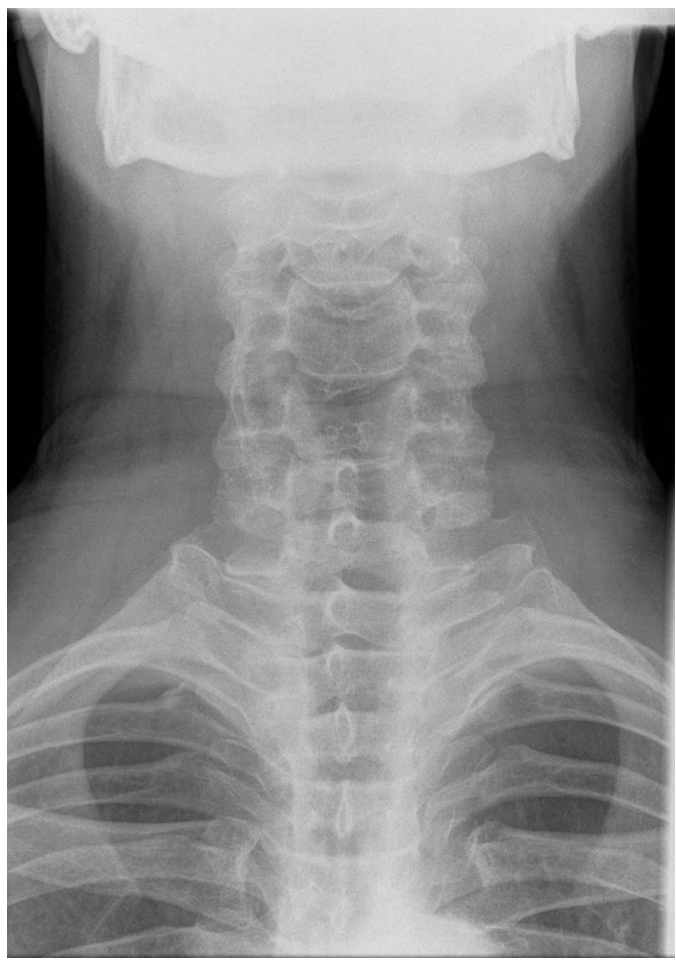

Figure 1 Preoperative thoracic inlet radiograph.

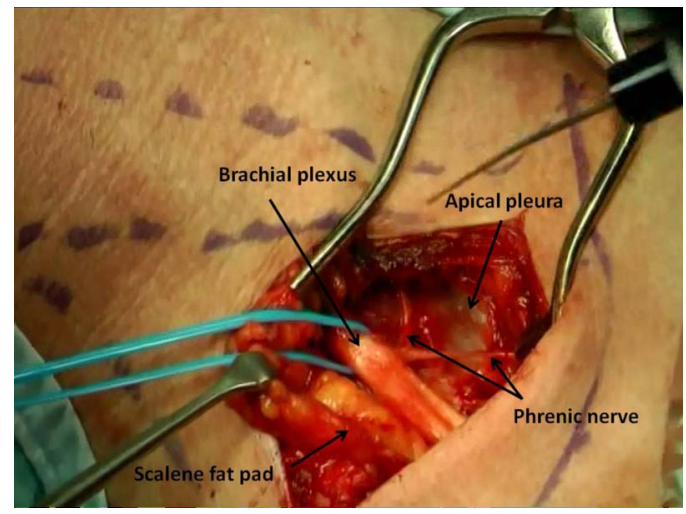

Figure 2 Intraoperative view of supraclavicular thoracic outlet decompression.

postoperative chest $\mathrm{x}$-ray excluded a pneumothorax (figure 6). Overall, the patient made an uneventful recovery.

This case shows that signs of thoracic outlet syndrome (TOS) can be subtle. Furthermore, various investigations help to confirm the diagnosis of TOS, as well as guide clinicians regarding the treatment options. TOS affects $<1 \%$ of population and results from compression of the neurovascular structures in the region of the thoracic outlet. ${ }^{1}$ The compression can be caused by the cervical ribs, fibromuscular tissue bands, bulky scalene muscles or previous neck trauma. ${ }^{2}$ The most important anatomical space in the thoracic outlet is the interscalene triangle, which is bounded by the scalene muscles (anterior and middle), which comprise the sides of the scalene triangle and the first rib forming the base of the triangle. ${ }^{3}$ Through this relatively small space, the SCA, SCV and nerves of brachial plexus pass.

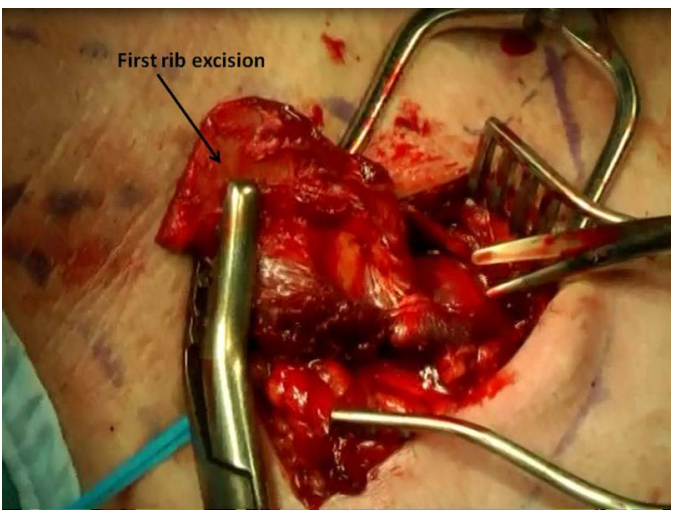

Figure 3 Excision of the first rib. 


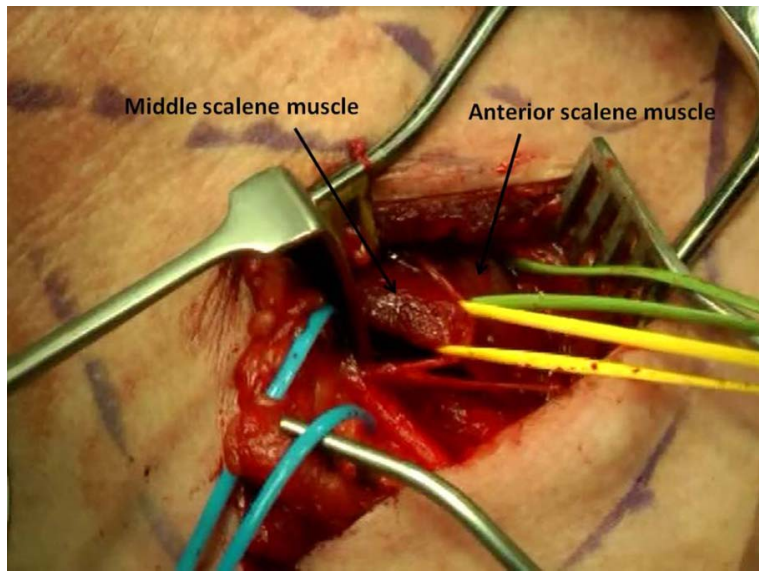

Figure 4 Hypertrophied scalene muscles.

Thus, the patient's symptoms and the subsequent type of TOS depend on which neurovascular structures are compressed. ${ }^{4}$ The most common type is neurogenical TOS (95\%) (nTOS), followed by venous (2-4\%) (vTOS) and arterial (1\%) (aTOS). ${ }^{1}$

The clinical diagnosis is challenging as many of the TOS symptoms overlap between various specialties including neurosurgery and orthopaedics. ${ }^{5}$ In addition, frequently performed Adson's test (obliteration of radial pulse on arm abduction) lacks sensitivity and specificity. ${ }^{5} 7$ This was well demonstrated in studies, where authors showed that obliteration of the radial pulse can be present in healthy subjects. This represents a positional occlusion of SCA, which is a normal finding. ${ }^{7}$ Although, Roos' test (shoulders at $90^{\circ}$ abduction with elbows flexed at $90^{\circ}$ ) was found to be more reliable in physical examination, its application is predominantly limited to the diagnosis of nTOS. ${ }^{5}$ Plain chest or cervical spine $\mathrm{x}$-ray can demonstrate cervical ribs or elongated C7 transverse processes. ${ }^{1}$ MRI can detect radiolucent bands, which compress the neurovascular bundle and are useful in patients with previous neck or spinal trauma as both these conditions can mimic TOS. ${ }^{8}$ Stenosis or occlusion of the SCA and SCV can be revealed by the UDS, which is an inexpensive, non-invasive and highly sensitive imaging modality. 69 When UDS imaging is equivocal additional tests such as CT angiography (CTA) and angiography/venography can be performed. ${ }^{8}$ CTA produces high-quality images allowing for careful assessment of the point of vascular compromise in relation to surrounding bones and soft tissues. Traditional tests such as angiography/venography are not only diagnostic, but are therapeutic tools also. Angiography delineates vessels with great detail and helps to plan appropriate surgical vascular reconstructionwhereas, during venography, catheter-based thrombolytic therapy can be performed.

Treatment option depends on the type and severity of symptoms. ${ }^{4}$ nTOS is best managed with physiotherapy, but patients who fail the conservative treatment can benefit from surgical decompression. ${ }^{4}$ vTOS can present as an axillo-subclavian thrombosis and is treated with an anticoagulation (1-3 months) followed by a delayed surgery. ${ }^{4} 10$ aTOS presents usually as an emergency with an upper limb ischaemia due to compression of the SCA or emboli arising from the associated SCA aneurysm. ${ }^{9}$ Treatment of aTOS involves decompression with or without arterial reconstruction depending on the clinical picture. ${ }^{6}$ In general, surgical decompressive procedures include excision of the first or cervical rib with scalenectomy, excision of soft tissue bands and revascularisation. ${ }^{1}{ }^{8}$ However, the reported

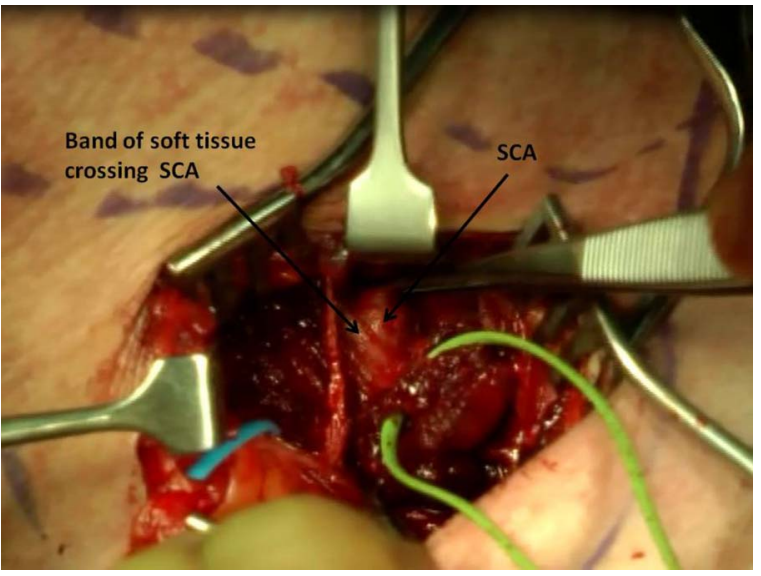

Figure 5 An abnormal tissue band compressing the subclavian artery.

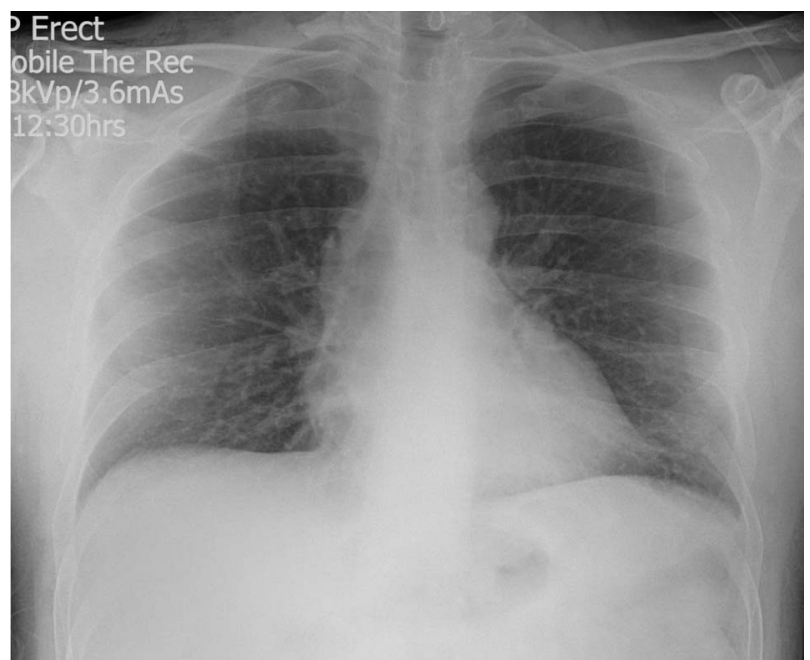

Figure 6 Postoperative chest radiograph confirming the excised right first rib and no pneumothorax.

postoperative morbidity can be as high as $40 \% .^{1}$ The complications are related to the important neurovascular structures within the very confined space of the thoracic outlet. The most commonly encountered complications include pneumothorax, haemothorax, chylous leak, brachial plexopathy, phrenic nerve injury, Horner's syndrome and vascular injury. ${ }^{1}$ Therefore, thorough clinical assessment supported by various investigations not only helps to establish the diagnosis, but also most importantly assists clinicians in careful and correct patient's selection prior to any surgical intervention.

\section{Learning points}

Thoracic outlet syndrome (TOS) can present with subtle signs of venous obstruction.

- A careful clinical assessment of the patient with suspected TOS is vital, but often lacks specificity and sensitivity.

- Additional investigations are required prior to any form of surgical intervention.

Competing interests None.

Patient consent Obtained.

Provenance and peer review Not commissioned; externally peer reviewed. 


\section{REFERENCES}

1 Cronenwett JL, Johnston W, Consult E. Rutherford's vascular surgery, 2-Volume Set E-Book. Philadelphia: Saunders, 2010.

2 Cordobes-Gual J, Lozano-Vilardell P, Torreguitart-Mirada N, et al. Prospective study of the functional recovery after surgery for thoracic outlet syndrome. Eur J Vasc Endovasc Surg 2008;35:79-83.

3 Drake RL, Vogl W, Mitchell AWM. Gray's anatomy for students. Philadelphia: Churchill Livingstone, 2005.

4 Fugate MW, Rotellini-Coltvet L, Freischlag JA. Current management of thoracic outlet syndrome. Curr Treat Options Cardiovasc Med 2009;11:176-83.

5 Roos DB. Congenital anomalies associated with thoracic outlet syndrome. Anatomy, symptoms, diagnosis, and treatment. Am J Surg 1976;132:771-8.
6 Davidovic LB, Kostic DM, Jakovljevic NS, et al. Vascular thoracic outlet syndrome. World J Surg 2003;27:545-50.

7 Nord KM, Kapoor P, Fisher J, et al. False positive rate of thoracic outlet syndrome diagnostic maneuvers. Electromyogr Clin Neurophysiol 2008;48: 67-74.

8 Beard JD, Gaines PA. Vascular and endovascular surgery. 4th edn. Edinburgh: Saunders, 2009.

9 Davidovic LB, Koncar IB, Pejkic SD, et al. Arterial complications of thoracic outlet syndrome. Am Surg 2009;75:235-9.

10 Jamieson CW. Venous complications of the thoracic outlet syndrome. Eur J Vasc Surg 1987;1:1-3.

Copyright 2013 BMJ Publishing Group. All rights reserved. For permission to reuse any of this content visit http://group.bmj.com/group/rights-licensing/permissions.

BMJ Case Report Fellows may re-use this article for personal use and teaching without any further permission.

Become a Fellow of BMJ Case Reports today and you can:

- Submit as many cases as you like

- Enjoy fast sympathetic peer review and rapid publication of accepted articles

- Access all the published articles

- Re-use any of the published material for personal use and teaching without further permission

For information on Institutional Fellowships contact consortiasales@bmjgroup.com

Visit casereports.bmj.com for more articles like this and to become a Fellow 